\title{
A educação superior na esteira da internacionalização
}

\author{
Higher education in the path of internationalization \\ La educación superior hacia el camino de la internacionalización
}

\section{OLGAÍSES CABRAL MAUÉS ANDRÉ RODRIGUES GUIMARÃES}

Resumo: O objetivo do artigo é analisar a concepção e o papel da internacionalização da educação superior a partir da ótica do Banco Mundial e da Organização para a Cooperação e o Desenvolvimento Econômico. Trata-se de pesquisa documental, fundamentada no materialismo histórico e dialético, cuja análise considerou os principais estudos publicados por tais organismos sobre a temática em questão. Constata-se que a internacionalização é defendida e utilizada como forma de privatização e mercadorização do conhecimento, enquanto uma "nova" estratégia para o capital. Em contraposição, defende-se a internacionalização da educação superior enquanto alargamento das fronteiras acadêmicas que considere, sobretudo, a educação como direito social e que atue na perspectiva da emancipação humana.

Palavras-chave: Educação Superior. Internacionalização. Organismos Internacionais.

Abstract: This paper aims to analyze the conception and the role of internationalization of higher education from the perspective of the World Bank and the Organization for Economic Cooperation and Development. This is a documentary research, based on historical and dialectical materialism, whose analysis considered the main published studies by such organizations about the theme under discussion. It is determined that internationalization is defended and used as a way of privatization and commercialization of knowledge, as a "new" strategy for the capital. Opposed to this, the internationalization of higher education is defended as a way of broadening the academic borders considering, especially, education as a social right which acts in the perspective of the human emancipation.

Keywords: Higher Education. Internationalization. International Organizations.

Resumen: El objetivo de este artículo es analizar la concepción y el papel de la internacionalización de la educación superior a partir de la mirada del Banco Mundial y de la Organización para la Cooperación y el Desarrollo Económico. Se trata de una investigación documental, fundamentada en el materialismo histórico dialéctico, cuyo análisis consideró los principales estudios publicados por tales 
organismos sobre la temática en cuestión. Se constata que la internacionalización es defendida y utilizada como una forma de privatización y mercantilización del conocimiento, como una "nueva" estrategia para el capital. En contraposición, se defiende la internacionalización de la educación superior como alargamiento de las fronteras académicas que considere, sobretodo, la educación como derecho social y que actúe en la perspectiva de la emancipación humana.

Palabras clave: Educación Superior. Internacionalización. Organismos Internacionales.

\section{INTRODUÇÃO}

Os Organismos Internacionais (OI), como o Banco Mundial (BM) e a Organização para a Cooperação e o Desenvolvimento Econômico (OCDE), vêm dando destaque às questões referentes ao processo de internacionalização do ensino superior, enquanto uma 'nova' estratégia para o capital e para o desenvolvimento econômico. Essas duas organizações expressam uma visão semelhante, ou muito próxima, em relação ao papel da educação superior para o crescimento econômico e uma compreensão parecida em relação ao sentido da internacionalização. Lauwerier (2017) informa que há uma aproximação de interesses entre esses OI, apesar da zona de intervenção de ambos diferir, na medida em que o BM atua mais diretamente nos ditos países em desenvolvimento e a OCDE nos países mais industrializados, ou mais desenvolvidos economicamente. Um dos traços de união desses OI é que ambos foram criados pós $2^{\mathrm{a}}$ Guerra Mundial, ${ }^{1}$ visando a prestar ajuda na reconstrução dos países que tinham sido devastados por esse conflito.

Ambos OI defendem a necessidade de adequação da educação aos interesses produtivos capitalistas, como pilar do desenvolvimento econômico. Para o BM o "desenvolvimento é principalmente sinônimo de crescimento econômico e de acesso ao mercado de trabalho" (LAUWERIER, 2017, p. 4). Para a OCDE, os pontos-chave do desenvolvimento são melhores empregos, estímulo ao crescimento e inclusão social. Ou seja, na visão desses organismos, o desenvolvimento de um país tem como centro a economia. Essa noção certamente também fundamenta a concepção de internacionalização da educação superior de tais organizações.

Nesse sentido, o objetivo deste estudo é analisar a concepção e o papel da internacionalização da educação superior a partir da ótica do BM e da OCDE. Trata-se de pesquisa documental que tem como base teórica o materialismo 
histórico e dialético e fonte de análise os principais estudos publicados sobre a temática publicados por esses organismos. Tal estudo está vinculado à pesquisa sobre Internacionalização da Educação Superior, os Organismos Internacionais e os Impactos nos Programas de Formação de Professores. ${ }^{2}$

Como desdobramento do método de investigação que fundamenta essa pesquisa, compreende-se que "o modo de produção da vida material condiciona o processo de vida social, política e intelectual” (MARX, 2008, p. 47). E, assim sendo, a análise da educação, mesmo nos casos dos sistemas ou subsistemas de ensino, deve considerar as condições materiais da produção vigente. Porém, também se faz necessário considerar a análise das contradições instituídas. Por isso, é fundamental considerar que os sistemas de ensino na sociedade capitalista,

\footnotetext{
Enquanto instrumento de conformismo científico-tecnológico, expressão contemporânea da sociabilidade humana, ao mesmo tempo em que veicula ideologias reprodutoras das relações sociais dominantes, veicula[m] também ideologias antagônicas e contraditórias. Nesse sentido, pode-se afirmar que a escola é, ao mesmo tempo reprodutora das relações socia s de produção capitalista e espaço de luta de classes, para superar estas relações. (NEVES, 2002, p. 23- 4).i
}

Considera-se, com base na perspectiva apresentada acima, que os documentos oficiais, particularmente os oriundos ou chancelados por OI, são objeto privilegiado de expressão das ideias dominantes. No caso particular do campo educacional, a OCDE e o BM, pelo papel que desempenham globalmente, constituem-se nos principais formuladores do pensamento hegemônico. Para desvelar as intenções que tais documentos e organismos carregam, bem como explorar suas contradições, sem ignorar, como aponta Fairclough (2001) que as palavras têm significados sociais que também expressam disputas de contextos mais amplos das lutas e embates estabelecidos socialmente, as quais envolvem a construção e consolidação de visões de mundo dominante - hegemonia.

Assim, discursos e textos da política, como os documentos dos OI aqui considerados, conforme Shiroma et al (2005, p. 431), "dão margem a interpretações e reinterpretações, gerando, como consequência, atribuição de significados e de sentidos diversos a um mesmo termo". E, recorrentemente, como ressaltam essas autoras, os significados e sentidos atribuídos apresentam-se em competição com outros, expressos por outros discursos e outros textos.

Trata-se, desse modo, de considerar que no tratamento dos documentos deste estudo, utiliza-se da análise do discurso. Isso se dá a partir da perspectiva também defendida por Marques; Andrade; Azevedo, p. 59), a qual "contempla, 
além de descrição, interpretação e compreensão do discurso como texto, também, e no mesmo grau de importância, a atribuição de sentidos ao discurso a partir do contexto histórico e das relações sociais em que este é produzido, distribuído e consumido". Em suma, deve-se compreender a materialidade histórica sobre a qual tais discursos são formulados e reformulados.

Desse modo, antes de analisar especificamente a concepção de internacionalização da educação superior, foco do presente estudo, discute-se, na seção seguinte, a função hegemônica da educação no capitalismo, particularmente no contexto de reestruturação produtiva. Em seguida, evidencia-se a visão do $\mathrm{BM}$ e da OCDE sobre o papel do ensino superior, enquanto fator que pode contribuir para impulsionar a chamada sociedade do conhecimento. A partir de tais elementos, analisa-se a função desempenhada pelos dois organismos internacionais em questão para o processo de internacionalização do ensino superior, bem como a concepção que os mesmos defendem em tal movimento.

\section{CENTRALIDADE DA EDUCAÇÃO PARA O DESENVOLVIMENTO DO CAPITALISMO}

Why education is the key to development foi o título do artigo publicado pelo Fórum Econômico Mundial, em julho de 2015. ${ }^{3} \mathrm{O}$ texto escrito por dois ministros noruegueses, Erna Solberg, Primeira-ministra, e Borge Brende, Ministro das Relações Exteriores (atual presidente do citado Fórum), foi um chamado para a Cúpula de Oslo sobre a Educação para o Desenvolvimento - realizada no mesmo ano na Noruega. A ideia motriz, a qual também expressa o posicionamento do Fórum, enfatiza a educação como chave para o crescimento econômico e a superação da pobreza.

Essa concepção economicista da educação não é nova. Tal perspectiva tem sua origem na Teoria do Capital Humano (SCHULTZ, 1973), desenvolvida no início da segunda metade do século XX. Como analisa Frigotto (1999), essa noção afirma-se no campo da economia na década de 1950 e, no campo educacional, nas duas décadas seguintes. Em síntese, defende-se a formação da mão de obra como elemento central no desenvolvimento econômico capitalista. Isso evidencia o duplo papel da educação nesse sistema: a produção material e o controle ideológico-político. Assim, a educação se consubstancia em "importante instrumento das classes dominantes, em sua luta permanente pela manutenção e reprodução de seu domínio sobre as demais" (ROSSI, 1980, p. 41).

\footnotetext{
3 Artigo disponível em: <www.weforum.org/agenda/2015/07/why-education-is-the-key-todevelopment>.
} 
Para Frigotto (1999), a Teoria do Capital Humano é um desdobramento da teoria neoclássica de desenvolvimento econômico. Essa abordagem considera que há um nexo direto entre o nível de educação e o desenvolvimento econômico. Indivíduos, regiões ou países desenvolvidos economicamente são aqueles que apresentam um capital humano elevado. Assim, defende-se, na lógica burguesa, que o investimento básico do crescimento econômico é a educação escolar.

Tal concepção é elemento basilar dos discursos e documentos orientadores de reformas educacionais, produzidos pelos organismos financeiros internacionais. Essa noção também fundamenta a reconfiguração das políticas desse campo, implementadas no contexto da crise capitalista desencadeada a partir do último quartel do século XX. Porém, nesse movimento, para responder às novas demandas laborais e mercantis, essa teoria se metamorfoseia, passa por processos de rejuvenescimento (FRIGOTTTO, 1999).

A exaltação do papel da educação para o crescimento econômico é, sobretudo, a construção ideológica para manutenção do sistema capitalista. $\mathrm{Na}$ prática, constitui-se em estratégia que busca omitir que as desigualdades sociais, o desemprego, o subemprego e a recessão econômica têm suas origens no campo das estruturas produtivas, centradas na exploração humana. Transfere-se para o âmbito da escolarização, da formação da classe trabalhadora, ou para a sua ineficiência, o cerne de todas as mazelas sociais.

Entretanto, se tal perspectiva pode ganhar aceitação em períodos de crescimento econômico, em momentos de crise capitalista, suas bases são questionadas. A recessão da economia leva à ampliação do desemprego, fazendo com que mesmo pessoas ou países de elevado capital humano não se mantenham produtivos. Dessa forma, a exemplo do que presenciamos atualmente, há um exército de reserva de trabalhadores qualificados e desempregados ou subutilizados.

Para melhor compreensão desse processo na atualidade, faz-se necessário, ainda que brevemente, caracterizar a atual crise do capitalismo. Inicialmente, é oportuno destacar que o tal sistema produtivo produz, por sua própria natureza, suas crises. Dito de outra forma, não há capitalismo sem crises em variados âmbitos da sociabilidade humana e graus de profundidade. Assim, as "crises de intensidade e duração variadas são o modo natural de existência do capital: são maneiras de progredir para além de suas barreiras imediatas e, desse modo, estender com dinamismo cruel sua espera de operação e dominação" (MÉSZÁROS, 2010, p. 69, grifo do autor).

Porém, a crise atual desse sistema apresenta ineditismo histórico. No último quartel do século passado, entramos em "convergência histórica de um conjunto de crescentes contradições sócio-metabólicas do sistema mundial 
do capital" (ALVES, 2009, p. 219, grifo do autor). Trata-se da maior crise em extensão e profundidade desse sistema com "a eclosão [em escala planetária] de precipitações cada vez mais frequentes e contínuas" (ANTUNES, 2009, p. 49, grifo do autor). Marcadamente, um processo de depressão contínua, sem perspectivas de recuperação econômica em largo prazo, fato que demonstra a originalidade da crise atual e incomparabilidade com as anteriores (MÉSZÁROS, 2009).

Para analisar e perceber a "mais grave crise em todo o mundo hoje, devemos focar a atenção na crise do sistema do capital em sua inteireza, pois a crise do capital que ora estamos experimentando é uma crise estrutural que tudo abrange" (MÉSZÁROS, 2011, p. 2). Assim, ao observar o modo de produção em sua totalidade, percebe-se um contínuo processo de degradação em todas as dimensões do capital, com abrangência global e profundo movimento de degradação da vida humana.

Assim, intensifica-se o processo de degradação ambiental, da exploração da força de trabalho, com o consequente agravamento da miséria. Contraditoriamente, isso ocorre acompanhado da otimização das forças produtivas. Essa contradição se coaduna com outra, do avanço e da destruição, já que progresso e desperdício são inseparáveis. "Quanto mais o sistema destrava os poderes da produtividade, mais libera os poderes da destruição; e quanto mais dilata o volume da produção tanto mais tem de sepultar tudo sob montanhas de lixo asfixiante" (MÉSZÁROS, 2009, p. 73).

No centro desse processo, estão as relações produtivas. Nesse movimento, a expansão do sistema de capital ataca frontalmente o mundo do trabalho. Intensifica-se a produção e se ampliam as relações laborais precárias, cuja manifestação mais aguda é o desemprego estrutural, com o consequente agravamento da miséria. Essas são as manifestações e as retroalimentações mais nefastas da crise estrutural no mundo do trabalho (ANTUNES, 2009).

Na ótica capitalista, a recuperação do crescimento econômico dependeria da incessante modernização produtiva, com modelo produtivo flexível, capaz de se adequar sempre às novas demandas do mercado. Para tal, passou-se a defender a redução nos gastos produtivos, o uso de novas tecnologias, a reorganização da estrutura de produção e a criação de novos mercados e mercadorias. Em suma, a consolidação de um novo regime de acumulação, cujo centro é a flexibilidade das relações produtivas.

Para o âmbito da educação, essa conjuntura implica a redefinição dos processos formativos. O regime de acumulação flexível coloca, na esfera individual, a responsabilidade pela aquisição dos atributos necessários à produção. Ao mesmo tempo, com a adoção de medidas de cunho neoliberal, o atendimento educacional é colocado crescentemente como serviço que deve estar sob a égide 
do mercado. Redefinem-se, assim, objetivos de formação, como alerta Frigotto (1995), com o rejuvenescimento da Teoria do Capital Humano: o indivíduo é o único responsável por seu sucesso ou fracasso social, educacional e econômico. Esse processo, em curso "configurou a educação como um campo de exploração lucrativa para o capital em crise e aprofundou sua função política, econômica e ideo-cultural de reprodução da concepção burguesa de mundo" (LIMA, 2011, p. 87).

A educação é exaltada, ideologicamente, como a chave para o desenvolvimento. A ciência, a tecnologia, o conhecimento, para cumprirem tal projeto, devem atender às necessidades da economia globalizada, do mercado flexível. Com isso, "o papel social da universidade vem ganhando significativa centralidade, ao ser exigida uma nova relevância social [...] e, enfatiza-se, a perspectiva das suas finalidades sociais frente ás demandas econômicas" (FERREIRA; OLIVEIRA, 2011, p. 40, grifo dos autores). Nessa lógica, essas instituições devem adaptar-se aos novos tempos para contribuir na promoção da inovação e formação de sujeitos para a empregabilidade e o empreendedorismo.

Particularmente, a educação superior vem sendo ressaltada pelos OI como importante instrumento para superar os problemas econômicos e sociais vigentes. Assim, diante das transformações nas estruturas produtivas e comerciais do capitalismo globalizado, devem também as instituições de ensino superior, ou de educação terciária, como preconizam a OCDE e o BM, passar por adaptações organizacionais e curriculares, para contribuir para a formação de trabalhadores flexíveis, capazes de se adaptarem a tal processo.

Essa é a conjuntura na qual o processo de internacionalização da educação superior vem ocorrendo. Em síntese, a educação e o conhecimento passaram a ser considerados como forças produtivas. Da mesma forma que a ciência e a tecnologia estão, cada vez mais, voltadas para o mercado. Esse é o fundamento do projeto socioeducativo dos OI, com destaque para o ensino superior, conforme exposto a seguir, a partir da análise de documentos elaborados pelo BM e pela OCDE. A análise dos documentos desses organismos internacionais busca deixar claro o papel que é demandado desse nível de ensino, enquanto uma estratégia para acompanhar e promover essa etapa do capital.

\section{O BANCO MUNDIAL, A OCDE E A EDUCAÇÃO}

A educação superior vem ocupando um espaço significativo no cenário mundia; isso é o que revela uma publicação da OCDE (2015). Segundo essa Organização, se o ensino superior fosse uma indústria seria uma das maiores do mundo todo. Alguns dados reiteram essa assertiva: o valor criado por um 
diplomado é em torno de cem mil dólares, sendo superior ao que foi investido; o aumento do número de diplomados nesse nível de ensino, com idade entre 25 e 34 anos, nos países que compõem a Organização, vem aumentando, representando, em 2014, 41\% na faixa etária entre 25 e 34 anos. (OCDE, 2015).

Ao mesmo tempo, a internacionalização desse nível de ensino, sendo a parte mais visível a mobilidade estudantil, aumentou nos últimos anos. Em 2016, nos países da OCDE, cerca de 3,5 milhões de estudantes foram fazer um curso no exterior, com destaque para os Cursos de Mestrado (1 estudante em 10) e, no Doutorado, o número é ainda maior, sendo que alguns países, a França, por exemplo, recebe três vezes mais estudantes estrangeiros no doutorado do que nas outras etapas do ensino superior (OCDE, 2018a). Os dados permitem avaliar que há uma forte tendência da expansão do ensino superior aliada à internacionalização. Tais elementos tornam o estudo dessa temática importante e urgente, para que se acompanhem as ações que vêm sendo desenvolvidas nessa direção pelos países em geral, incluindo o Brasil.

A escolha do BM e da OCDE, como os organismos internacionais a serem analisados em relação à expansão e a internacionalização do ensino superior, está ligada ao papel que esses dois OI desempenham ao longo de suas existências, no tocante a esse nível de ensino. O que vem sendo materializado ora por documentos orientadores, ora por documentos elaborados em demanda de governos, como é o caso mais recente em relação ao Brasil. Em 2017, o Banco Mundial publicou o documento Um Ajuste Justo (BM, 2017). Trata-se de uma análise da eficiência e equidade do gasto público no Brasil, no qual se dedica uma seção para discorrer sobre a eficiência e equidade da educação pública. Já a OCDE, em 2018, publicou o resultado de um trabalho intitulado Repensando a Garantia de Qualidade para o Ensino Superior no Brasil, no qual faz recomendações a respeito desse nível de ensino. Além desses dois e mais recentes documentos, o BM e a OCDE têm uma longa tradição de cooperação técnica com o Brasil, além de poderem ser considerados Thin Tank em relação à educação superior, no mundo.

Para melhor se entender o papel que o BM vem desempenhando em várias áreas, com destaque para a educação, é importante esclarecer qual a missão que essa instituição se coloca: "Nós somos uma das principais fontes de financiamentos e de conhecimento para os países em desenvolvimento e nós compartilhamos o mesmo desejo de lutar contra a pobreza, de aumentar a prosperidade e de promover um desenvolvimento durável” (BM, 2018, p. 1). Os objetivos apresentados no site da instituição são claros em relação a dois aspectos: colocar fim à extrema pobreza e promover uma prosperidade partilhada de modo 
durável. ${ }^{4}$ Há uma insistência, presente em praticamente todos os documentos, que indica o objetivo dessa instituição de ajudar o poder público e as populações a colocarem fim à pobreza e a suplantar alguns desafios urgentes em matéria de desenvolvimento.

Em relação à educação, o BM se posiciona dizendo que é um poderoso vetor de desenvolvimento e um dos melhores meios de reduzir a pobreza, de aumentar os níveis de saúde e de promover a igualdade entre os sexos e desenvolver a paz e a estabilidade. É com esta lógica que tal OI tem-se voltado, há algum tempo, para a análise da educação superior, considerada fundamental para fomentar o crescimento econômico e reduzir a pobreza. O BM defende que a força de trabalho altamente qualificada, com um ensino superior sólido, é indispensável para promover a inovação e o crescimento.

Dessa forma, em 1994, esse organismo publicou um documento intitulado L'enseignement superieur: les leçons de l'experience, no qual são feitas algumas recomendações consideradas importantes e que vêm mudando a natureza e os objetivos desse nível de ensino, desde então. As principais 'lições', segundo o $\mathrm{BM}$, indicavam que o ensino superior estava em crise e, por isso, seria necessário adotar as seguintes estratégias: diferenciação das instituições e de suas missões, inclusive a criação de instituições não universitárias; diversificação das fontes de financiamento para a educação pública, mobilizando os fundos privados; redefinição do papel do Estado, aumentando a autonomia e a responsabilidade do setor público (BM, 1994). Pode-se dizer que esse documento é um marco para a educação superior, que passou, praticamente em todo o mundo, a seguir essas 'diretrizes'.

Nos anos 2000, outros documentos foram elaborados e as 'lições' do século XX foram atualizadas e revigoradas, ganhando força e densidade. Assim, em 2003, é divulgado Construir les sociétés du savoir. Nouveaux défis pour l'enseignement supérieur, (doravante denominado Construir les sociétés) no qual, conforme anunciado no título, é feita uma análise do papel que é esperado desse nível de ensino nessa suposta nova organização social.

Já no prefácio do documento para a edição francesa, é explicitada a mudança de posição do $\mathrm{BM}$ em relação à educação superior. A partir de sua avaliação, indica-se uma correlação entre esse nível de ensino e o desenvolvimento de uma nação, devendo assim ser uma prioridade. Portanto, o documento Construir les sociétés representa uma virada na concepção do BM sobre o papel, os objetivos e a função do ensino superior para o desenvolvimento dos países chamados, à época da elaboração do relatório, de emergentes e para a construção

4 Em relação à pobreza, a meta é reduzir para 3\% as pessoas que vivem com menos de $\$ 1,90$ dólar, até 2030, procurando favorecer cada país ao crescimento da renda dos mais pobres em $40 \%$. 
da sociedade do conhecimento. Alguns motivos para que essa mudança ocorresse estão explicitados, destacando-se aqueles referentes ao papel que o conhecimento passou a desempenhar, sendo considerado o principal motor do desenvolvimento econômico; novas configurações de instituições de ensino superior; o crescimento da tendência de uma educação sem fronteiras, em função da mundialização da economia; e o surgimento de um mercado mundial para o capital humano de alto nível, ou seja, a importância da internacionalização.

A partir desses aspectos, o BM elabora orientações e diretrizes para fazer face a essas novas demandas, no sentido de que o ensino superior possa contribuir efetivamente para a criação da sociedade do conhecimento. $\mathrm{O}$ documento em análise traz uma abordagem sobre a mundialização da economia e indica o papel que o ensino superior pode desempenhar nesse contexto. A primeira coisa colocada em destaque é a importância do saber como força produtiva fundamental para a sociedade do conhecimento. Para esse organismo, o processo de mundialização acelera a importância do conhecimento, que se coloca, cada vez mais, no centro das vantagens comparativas de um país. Essas deixam de ser "a abundância dos recursos naturais ou a disponibilidade de uma mão de obra barata" e passam a ser "mais e mais as inovações técnicas e a utilização competitiva do conhecimento" (BM, 2003, p. 36).

Nessa lógica, o ensino superior seria "um dos elementos mais determinantes do conjunto de fatores complexos que definem o fator de produtividade total de um país" (BM, 2003, p. 39). O BM destaca que outros fatores também devem ser considerados para esse crescimento, dentre eles, as políticas econômicas e o contexto político.

Esse documento (BM, 2003) também dá destaque a uma posição anterior dessa instituição já referida neste texto, e a reforça, relativa à diversificação da organização administrativa dos estabelecimentos de ensino superior, tendo como objetivo o atendimento de uma demanda crescente por esse nível de ensino, sobretudo, pela via do setor privado. Pela importância e o sentido que é dado ao ensino superior, o Banco indica diferentes possibilidades de ter acesso a esse nível de ensino, abrindo também a possibilidade de serem realizados cursos via universidades virtuais, muitas vezes situadas em outros países. A internacionalização é vista como forma eficiente de oferta de cursos, incluindo as franquias, por exemplo. Outra forma, recomendada nessa diversificação, é a flexibilização dos cursos, dos programas, dos currículos, que devem vencer as barreiras burocráticas, a fim de atender às demandas postas pelo que o BM denomina de sociedade do conhecimento.

O documento Construir les sociétés dedica um capítulo para tratar da “evolução das relações entre as instituições de ensino superior, o mercado e o 
Estado" (Idem, p. 115). A abordagem coloca em destaque o papel que o mercado deve desempenhar na definição dos cursos, dos programas, da gestão das instituições de ensino superior, universitárias ou não universitárias. Chama-se a atenção ao fato de que o Estado deve estar mais atento aos sinais, no sentido de atendê-los, sobretudo, criando facilidades para que a iniciativa privada possa 'contribuir' para o aumento da demanda de novas matrículas.

O documento do BM (2003) finaliza defendendo a importância do ensino superior para a construção da sociedade do conhecimento e do crescimento econômico dos países em desenvolvimento e em transição, apresentando algumas mensagens importantes, para uma reflexão, tais como: "O progresso social e econômico se realiza principalmente pelo avanço e aplicação do conhecimento; o ensino superior é necessário para a criação e difusão e aplicação do conhecimento e para o reforço das capacidades técnicas e profissionais" (p. 7). Na sequência, o documento esclarece o fato de que "os países em desenvolvimento [...] correm o risco de serem marginalizados em uma economia mundial altamente concorrente, caso seus sistemas de ensino superior não sejam suficientemente preparados para participar da criação e da utilização do conhecimento" (Idem, p. 8). E por último, mas muito importante, é apresentada uma mensagem que implica no papel do Estado enquanto responsável por dar condições para que o ensino superior seja inovador o suficiente para fazer face ao conhecimento concorrencial mundial e, também, de propiciar meios para que esse nível de ensino se adapte às "condições mutantes do mercado de trabalho" (Ibidem), formando um capital humano de alto nível. E para que isso possa ocorrer, esse organismo internacional anuncia que pode ajudar os países clientes a aproveitar da experiência acumulada da instituição, mobilizando recursos para tornar os sistemas educacionais melhores para atingirem seus objetivos.

O documento em análise demonstra o interesse do $\mathrm{BM}$ em contribuir para o ensino não universitário, para a ampliação do setor privado, para o descompromisso do Estado com o financiamento público, e, sobretudo, para instalar um ensino superior com o objetivo fundamental de preparar as pessoas para o atendimento ao mercado, ${ }^{5}$ em nível mundial, via internacionalização. Ou seja, há um forte alinhamento dessas recomendações com a Teoria do Capital Humano, abordada anteriormente. Tais indicações, como será analisado a seguir, têm semelhanças com as orientações da OCDE.

5 A utilização do termo mercado neste texto tem a seguinte conotação: “O termo 'mercado' é a palavra que serve hoje para designar pudicamente a propriedade privada dos meios de produção; a posse de ativos patrimoniais que comandam a apropriação sobre uma grande escala de riquezas criadas por outrem; uma economia explicitamente orientada para os objetivos únicos de rentabilidade e de competitividade e nas quais somente as demandas monetárias solventes são reconhecidas” (CHESNAIS, 2001, p. 1). 
A OCDE foi criada em 1948 para gerenciar o Plano Marshall, tendo como missão "promover as políticas que melhorem o bem estar econômico e social no mundo todo" (OCDE, 2018b, p. 1). Por ocasião dos festejos dos 50 anos de existência desse OI, essa missão foi reforçada e ampliada, devendo realizar "a promoção de um crescimento econômico mais forte, mais saudável, mais justo, melhorando o emprego e o nível de vida". Para tanto, essa organização procura identificar "os principais desafios econômicos, sociais e ambientais que os governos enfrentam, desenvolvendo políticas para promover o bem estar das pessoas em todo o mundo" (OCDE, 2018b, p. 1).

O papel que a OCDE atribui à ciência, à tecnologia e à educação fica evidenciado nos objetivos: "promover a inovação tecnológica para acelerar a economia, protegendo o meio ambiente [...]; incentivar um sistema de educação global para garantir que a próxima geração de trabalhadores tenha as ferramentas necessárias para o crescimento da economia" (OCDE, 2018b, p. 1). Como se observa, a economia está no centro da sua missão, dos seus objetivos e das suas estratégias, não havendo destaque para o desenvolvimento social.

Seguindo o mesmo diapasão, concernente ao papel do ensino superior, a OCDE publicou, em 2008, um relatório intitulado Enseignement supérieur pour la société de la connaissance", (doravante "Enseignement supérieur'). Esse documento será objeto de análise, buscando-se extrair as principais concepções, os conceitos e as recomendações apresentadas, visando a compreender a relação que esse organismo estabelece entre o ensino superior e o crescimento econômico.

O documento em questão apresenta o relatório de uma enquete, realizada em 24 países, ${ }^{6}$ acerca das políticas de ensino superior, abrangendo as dimensões referentes à governança, ao financiamento, à garantia de qualidade, à equidade, à pesquisa e à inovação, à carreira universitária, às ligações com o mercado e à internacionalização. Os resultados apontam algumas políticas que podem garantir, na visão da OCDE, a contribuição do ensino superior aos objetivos econômicos e sociais do país.

A OCDE (2008), assim como o BM (2003), coloca o ensino superior como um fator fundamental de competitividade econômica, em um contexto de uma economia mundial que depende, cada vez mais, do conhecimento. Por isso, é importante, para esse organismo, criar condições para a expansão desse nível de à pesquisa e à difusão do conhecimento.

6 Austrália, Bélgica (comunidade flamenga), Chile, China, Coréia, Croácia, Espanha, Estônia, Rússia, Finlândia, França, Grécia, Islândia, Japão, México, Noruega, Nova Zelândia, Países Baixos, Polônia, Portugal, República Tcheca, Reino Unido, Suécia e Suíça. 
O relatório (OCDE, 2008) explicita que o ensino superior contribui efetivamente para o desenvolvimento econômico e social de quatro maneiras: na formação do capital humano; na constituição de base de conhecimento; na difusão do conhecimento; na conservação do conhecimento, visando à transmissão intergeracional.

A pesquisa, realizada pela OCDE (2008), também indica as principais tendências desse nível de ensino, com destaque para a expansão, a diferenciação da oferta, a diversificação do financiamento. Além do fundo público, outras fontes (mercado, empresas, famílias) são desejáveis, devendo esse tipo de financiamento estar vinculado aos resultados apresentados, em uma lógica da produtividade tão bem identificada nas políticas brasileiras. Além dessas, o documento em questão aponta duas outras tendências: a internacionalização, via criação de redes de contatos e parcerias, e a nova forma de gestão, com uma configuração muito próxima àquela utilizada pelas empresas privadas. Para a OCDE, um dos desafios do ensino superior é a formulação de políticas e estratégias de internacionalização, além da importância das instituições de ensino superior tornarem-se atores proativos nesse processo.

A partir do sentido dado pelo BM e pela OCDE à educação superior, podese analisar e compreender o papel que esses organismos atribuem ao processo de internacionalização desse nível de ensino, ou a sua dimensão internacional, no sentido de ampliar o raio de ação das instituições educacionais privadas e públicas.

\section{A INTERNACIONALIZAÇÃO DA EDUCAÇÃO SUPERIOR}

A compreensão de qual seja o papel e a natureza da internacionalização tem sido muito debatida, não havendo um consenso relativo à concepção do que seja essa ação. O próprio surgimento da Universidade pode ser caracterizado como tendo um caráter internacional, mas, na atualidade, esse termo ganha configurações polissêmicas.

Segundo Knight (1999), o termo internacionalização tem sofrido mudanças de sentido através do tempo. Têm-se apresentado diferentes abordagens que são dadas ao termo, resultando em várias definições. Para essa autora, "a internacionalização do ensino superior é o processo de integração de uma dimensão internacional/intercultural nas funções de ensino, de pesquisa e de serviço nas instituições" (p.18).

A mesma autora, em 2005, em documento organizado pela OCDE, intitulado L'enseignement supérieur en Amérique Latine. La Dimension Internationale, apresenta uma definição mais ampla, demonstrando e defendendo que a internacionalização é um processo e, como tal, não cessa de se transformar. Nesse 
documento, a compreensão é de que a definição deve ser mais geral, a fim de que possa ser aplicada a vários países, culturas e sistemas de ensino diferentes, podendo adaptar-se a um conjunto de contextos de diversos países e regiões do mundo. A "nova" definição acentua que a internacionalização é "o processo que consiste em integrar uma dimensão internacional, intercultural ou mundial às finalidades, às funções ou à organização do ensino pós-secundário" (KNIGHT, 2005, p. 22).

Mas as mudanças continuam e, em 2015, Knight destaca que, nos últimos 20 anos, esse termo tem sido objeto de muitas discussões e embates, sobretudo a partir dos anos de 1980. É interessante notar o destaque dado à utilização do termo que, segundo Knight (2015), nos anos 90 do século XX, tinha relação direta com educação comparada, educação global e educação multicultural, sendo que, na primeira década do século XXI, a internacionalização está vinculada a outro conjunto de termos conexos, tais como educação transnacional, educação sem fronteiras, e educação transfronteiriça.

Em 2015, o Parlamento Europeu publica o resultado de um estudo, no qual é apresentada uma definição revisada e ampliada da definição de internacionalização, em relação àquelas de Knight (1999, 2005, 2015). Em tal definição, a internacionalização se configura como

Processo intencional de integração das dimensões internacionais, interculturais ou mundiais às finalidades, às funções e à prestação do ensino pós-secundário, a fim de melhorar a qualidade do ensino e da pesquisa para todos os estudantes e pessoal acadêmico e administrativo e trazer uma contribuição útil à sociedade (PARLAMENTO EUROPEU, 2015, p. 31).

Percebe-se a preocupação com a qualidade que, doravante, passará a ser uma constante desse processo.

A OCDE e o BM publicaram conjuntamente, em 2008, um documento intitulado L'enseignement supérieur transnational: Un levier pour le développement, no qual esclarecem que o ensino transnacional é uma das manifestações da internacionalização, o que veio a ser corroborado por Knight (2015).

Como se vê, a utilização do termo não é tão tranquila. Azevedo (2015) destaca que a internacionalização está relacionada à solidariedade e à interculturalidade; já a transnacionalização está associada à mercnatilização. Para Bernheim (2008), a internacionalização segue os princípios da Declaração Mundial sobre Educação Superior, que defende uma cooperação solidária, horizontal, baseada no diálogo, respeitando as diferenças e a identidade dos países parceiros. Enquanto a transnacionalização transforma a educação em "um serviço sujeito às regras do mercado, com predomínio dos interesses das empresas de educação 
transnacional. [...] trata-se de facilitar o estabelecimento em nossos países de afiliadas de universidades estrangeiras" (BERNHEIM, 2008, p. 314). A diferença, pois, entre as duas correntes - internacionalização e transnacionalização - é muito significativa, sendo que essa última envolve o surgimento de franquias acadêmicas, universidades corporativas, ensino a distância, dentre outras formas de oferta de ensino, com um forte caráter comercial, incluindo a mobilidade de estudantes, de programas e de pesquisadores.

O documento elaborado pela OCDE e BM (2008) apresenta a importância e, mesmo, a necessidade de se realizar a transnacionalização do ensino superior. Para esses organismos, o ensino superior transnacional representa o deslocamento de pessoas, programas, cursos, projetos, atividades de pesquisa, parcerias acadêmicas, abertura de franquias para além das fronteiras de um país. O objetivo principal desse tipo de ação, segundo a OCDE e o BM, é a formação de um capital humano altamente qualificado, para o reforço das capacidades que permitirão o desenvolvimento de um país. Novamente, percebe-se a relação com a Teoria do Capital Humano abordada anteriormente.

Para esses OI, as principais estratégias utilizadas para o desenvolvimento do ensino superior transnacional são: 1. A mobilidade de estudantes, de professores e de pesquisadores; 2. A mobilidade de Programas ofertados por um país a outro, podendo ser pela via da presença física dos 'fornecedores', ou por meio virtual; 3. A prestação de serviços ou o fornecimento, no caso a mobilidade, é do estabelecimento de ensino que se desloca para se estabelecer em outro país, seja via abertura de um 'campus satélite', ou abrindo um estabelecimento (dependendo das leis do país), ou ainda comprando parte de um estabelecimento local. ${ }^{7}$ A OCDE e o BM deixam claro que essas estratégias são, na maioria das vezes, desenvolvidas com o objetivo de gerar recursos aos países que fazem a oferta. Ou seja, o caráter comercial está presente de forma muito clara e explicita, sendo uma atividade lucrativa, na lógica do Acordo Geral de Comércio e Serviços (AGCS) que transformou a educação em mercadoria.

Em tal documento, enfatiza-se a importância do Acordo Geral de Comércio e Serviços, sob a égide da Organização Mundial do Comércio (OMC), como um recurso para possibilitar a expansão do ensino superior, via transnacionalização, na medida em que muitos países, sem esse tipo de parceria, não teriam condições financeiras, de infraestrutura e de pessoal para realizar essa ampliação. E pelo papel que o ensino superior pode desempenhar para o crescimento econômico de um país, faz-se necessário promover os meios que 
tornem essa tarefa possível e viável. Para esses organismos, o ensino superior transnacional, para além de ampliar o número de pessoas com acesso a esse nível, é, sobretudo, capaz de reforçar as capacidades dos recursos humanos de um país, tornando-os mais produtivos, logo, mais rentáveis.

Pela abordagem dada pelo documento da OCDE e do BM (2008), a transnacionalização do ensino superior tem a finalidade clara de ser uma mercadoria importante para essa etapa do capitalismo. O título do documento, produzido por esses dois organismos, indica que esse tipo de ensino transnacional é uma alavanca para o desenvolvimento econômico de um país, indo além de uma política educacional, integrando-se às políticas e às estratégias econômicas. Esse tipo de ensino pode ajudar a reforçar a oferta de formação de capital humano para a economia mundial.

O caráter comercial e mercadológico do ensino superior transnacional está bem explicitado em outro documento da $\operatorname{OCDE}$ (2004, p. 33), informando que "para a economia de um país, a escolarização de um estudante estrangeiro representa uma 'exportação invisível' por meio do fluxo de receita que é gerada". Em 2004, esse fato representava 30 bilhões de dólares americanos. Essa informação pode dar uma noção do interesse do setor privado de fomentar o ensino superior transnacional. Na lógica da mundialização do capital, a formação de pessoal em nível superior se torna um recurso altamente conveniente que passa a ser considerado pelos governos, no sentido da liberalização desse tipo de comércio.

O ensino superior é visto como forma de promover o desenvolvimento econômico de um país. $\mathrm{O}$ ensino superior transnacional reforça esse objetivo, juntando-o à importância da comercialização e mercantilização, via sua transnacionalização.

Não se quer dizer com isso que a internacionalização seja algo negativo. No mundo globalizado, a educação não pode ficar isenta desse processo. Mas o que está em questão não é a internacionalização, no sentido da cooperação, da solidariedade entre países, em uma relação horizontal. O que se questiona é a transnacionalização na lógica apresentada pelo BM e pela OCDE, que seguem as normas do Acordo Geral de Comércio e Serviços, que transformou a educação em um serviço comercial que, como tal, precisa ser lucrativo.

$\mathrm{Na}$ medida em que o ensino superior deve ter o caráter de uma alavanca para o desenvolvimento de um país, como defendem os OI, o ensino superior transnacional deve contribuir para a expansão desse nível de ensino, propiciando a possibilidade de se ter uma grande mobilidade de estudantes, de programas, 
de estabelecimentos, de extensão de campus, de compras ou parcerias com instituições locais, o que amplia em muito o lucro a ser alcançado. A questão está posta para os governos, entre a internacionalização e a transnacionalização, ou entre a cooperação e a lucratividade.

\section{CONSIDERAÇÕES FINAIS}

A educação superior tem sido colocada como uma ferramenta importante para o crescimento econômico dos países, desde que amplie seus objetivos, devendo internacionalizar-se para permitir uma troca maior do conhecimento. Nessa perspectiva, a internacionalização é um fator fundamental. Contudo, na análise que se realizou neste texto, evidenciou-se que a internacionalização da educação superior vem sendo utilizada como transnacionalização, o que significa uma forma de privatização do conhecimento, seja nas instituições públicas seja privadas, contribuindo para a 'commoditização' da educação.

A internacionalização da educação superior é uma temática que vem ocupando as agendas de diferentes instituições internacionais e nacionais, no sentido da inserção desse nível de ensino na globalização que caracteriza o mundo nos dias atuais. O objetivo central desse tipo de internacionalização, que é a transnacionalização, é a preparação de recursos humanos que correspondam à necessidade colocada por uma dita sociedade do conhecimento. Em contraposição a essa perspectiva, defende-se a necessidade de reafirmar e lutar pela internacionalização, enquanto movimento de solidariedade à interculturalidade, uma cooperação solidária, horizontal, dialógica, que respeite as diferenças dos países envolvidos e que se faça via ensino superior público, visando ao fortalecimento e ao desenvolvimento social dos países.

Nos tempos atuais, não há o que tergiversar; o ensino superior precisa internacionalizar-se, mas isso precisa ser feito em um registro diferente daquele defendido pelos organismos internacionais analisados neste texto. A internacionalização que se defende é aquela que contribua para o alargamento das fronteiras acadêmicas, na lógica da educação enquanto direito inalienável de todas as pessoas, buscando-se a emancipação humana e social. 


\section{REFERÊNCIAS}

ALVES, G. O novo (e precário) mundo do trabalho: reestruturação produtiva e crise do sindicalismo. São Paulo: Boitempo, 2009.

ANTUNES, R. A substância da crise e a erosão do trabalho. In: SAMPAIO JUNIOR, P. A. (Org.). Capitalismo em crise: a natureza e dinâmica da crise econômica mundial. São Paulo: Editora Instituto José Luís e Rosa Sundermann, 2009.

AZEVEDO, M. L. N. Internacionalização ou transnacionalização da educação superior: entre a formação de um campo social global e um mercado de ensino mundializado. Crítica Educativa, Sorocaba, v. 1, n. 1, p. 56-79, jan./jun.2015.

BERNHEIM, C.T. La calidad de la educación superior y su acreditación: la experiencia centroamericana. Revista Avaliação, Campinas, Sorocaba, v. 13, n. 2, p. 313-336, jun. 2008.

BM - BANQUE MONDIALE. Notre Mission. 2018. Disponível em:<http:// www.banquemondiale.org/fr/what-we-do>. Acesso em: 02 out. 2018.

Um ajuste justo: Análise da eficiência e equidade do gasto público no Brasil. Washington: Banco Mundial, 2017. Disponível em: < http://documents. worldbank.org/curated/en/884871511196609355/pdf/121480-REVISEDPORTUGUESE-Brazil-Public-Expenditure-Review-Overview-PortugueseFinal-revised.pdf>. Acesso em 08 out. 2018.

BM; OCDE. L'enseignement supérieur transnational: Un levier pour le développement. 2008. Disponível em: <http:/ / www.oecd.org/fr/education/innovation-education / lenseignementsuperieurtransnationalunlevierpourledeveloppement.htm>. Acesso em: 22 dez. 2017.

Construire les sociétés du savoir. Nouveaux défis pour l’enseignement supérieur. Quebec: Les Presses de l’Université Laval, 2003. 
. L'enseignement superieur: les leçons de l'experience. Washington: Banque Mondiale, 1994. Disponível em: <http://documents.banquemondiale. org/curated/fr/502701468326672044/pdf/133500French0L1ement120superieu r1fr.pdf>. Acesso em: 02 set.2018.

CHAVES, V. L. J.; REIS, L. F.; GUIMARÃES, A. R. Dívida pública e financiamento da educação superior no Brasil. Acta Scientiarum, v. 40, n. 1, p. 1-12, 2018. Disponível em: $<$ http://periodicos.uem.br/ojs/index.php/ActaSciEduc/article/ view/37668/21760>. Acesso em 10 out. 2018.

CHESNAIS, F. Mundialização: O Capital Financeiro no Comando. Revista Outubro, $5^{a}$ Ed., p. 1-22, 2001. Disponível em: <http://outubrorevista.com.br/ wp-content/uploads/2015/02/Revista-Outubro-Edic\%CC\%A7a\%CC\%83o-5Artigo-02.pdf>. Acesso em: 19 maio 2018.

FAIRCLOUGH, N. Discurso e Mudança Social. Brasília: Editoria da UnB, 2001.

FERREIRA, S.; OLIVEIRA, J. F. As influências da reforma da educação superior no Brasil e na União Européia nos papéis sociais da universidade. In: OLIVEIRA, J. F. (Org.). O campo universitário no Brasil: políticas, ações e processos de reconfiguração. Campinas: Mercado de Letras, 2011.

FÓRUM ECONÔMICO MUNDIAL. Why education is the key to development. 2015. Disponível em: <www.weforum.org/agenda/2015/07/ why-education-is-the-key-to-development>. Acesso em: 10 jul. 2018.

FRIGOTTO, G. A produtividade da escola improdutiva: um (re)exame das relações entre educação e estrutura econômico-social e capitalista. $5^{a}$ ed. São Paulo: Cortez, 1999.

. Educação e a crise do capitalismo real. São Paulo: Cortez, 1995.

KNIGHT, J. Updating the Definition of Internationalization. International Higher Education, n. 33, p. 2-3, 2015. Disponível em: < https://ejournals. bc.edu/ojs/index.php/ihe/article/viewFile/7391/6588>. Acesso em: 10 out. 2018. 
Modèle d'internationalisation ou comment faire face aux réalités et enjeux nouveaux. In: OCDE. L'Enseignement supérieur en Amérique Latine. La Dimension Internationale. Paris: Les Editions de L'OCDE, 2005. p. 11-45. Disponível em:<http://siteresources.worldbank.org/EDUCATION/ Resources/278200-1099079877269/547664 1099079956815/Higher_Ed_in_ LAC_Intnal_Dimension_FR.pdf>.Acessoem: 04 jan. 2017.

.Internationalisation de l'enseignement supérieur. In: OCDE. Qualité et Internationalisation de l'Enseignement Supérieur. Paris: Les Editions de L'OCDE, 1999. p. 15-31. Disponível em: < http://ifgu.auf.org/media/document/ Qualit\%C3\%A9_et_internationalisation_de_lenseignement_sup $\% \mathrm{C} 3 \% \mathrm{~A}$ 9rieur. pdf>.Acesso em: 20 maio 2017.

LAUWERIER, T. L'Éducation au Service du Developpement. La vision de la Banque Mondiale, de l'OCDE et de l'UNESCO. Géneve. Revue L'Éducation em débats: analyse comparée, v. 8, p. 43-58, 2017.

LIMA, K. O Banco Mundial e a educação superior brasileira na primeira década do século. Revista Katálisys,v. 14, n.1, p. 86-94, 2011.Disponível em: $<$ http:/ / www.scielo.br/scielo.php?pid=S1414-49802011000100010\&script=sci_ abstract\&tlng=pt>. Acesso em: 15 set. 2018.

MARQUES, L. R; ANDRADE, E. F.; AZEVEDO, J. M. L. Pesquisa em política educacional e discurso: sugestões analíticas. RBPAE, v. 33, n. 1, p. 55-71, jan./ abr. 2017. Disponível em: < https://seer.ufrgs.br/rbpae/article/view/72834> . Acesso em 20 nov. 2018.

MARX, K. Contribuição à crítica da economia política. $2^{a}$ edição. São Paulo: Expressão Popular, 2008.

MÉSZÁROS, I. Crise estrutural necessita de mudança estrutural. In: ENCONTRO DE SÃO LÁZARO, 2., 2011, Salvador. UFBA/FFCH. Disponível em: <http://www.ffch.ufba.br/IMG/pdf/Conferencia_Meszaros.pdf>. Acesso em: 20 jan. 2018.

Atualidade histórica da ofensiva socialista: uma alternativa radical ao sistema parlamentar. São Paulo: Boitempo, 2010. 
A crise estrutural do capital. São Paulo: Boitempo, 2009.

NEVES, L. M. W. Educação e política no Brasil de hoje. $3^{a}$ edição. São Paulo: Cortez, 2002.

OCDE - Organização para a Cooperação e o Desenvolvimento Econômico. Regardssurl'éducation, 2018a. Disponível em: <http://download.inep.gov.br/ acoes_internacionais/ocde/Repensando_a_Garantia_de_Qualidade_para_o_ Ensino_Superior_no_Brasil_PT.pdf>. Acesso em: 08 mai. 2019.

Notre Mission. 2018b. Disponível em: <http://www.oecd.org/fr/ apropos>. Acesso em: 06 maio 2018.

Regardssurl'éducation, 2015. Disponível em: <http://documents. worldbank.org/curated/en/884871511196609355/pdf/121480-REVISEDPORTUGUESE-Brazil-Public-Expenditure-Review-Overview-PortugueseFinal-revised.pdf>. Acesso em: 08 mai. 2019

. Enseignement supérieur pour la société de la connaissance. Rapport de synthèse. Paris: OCDE, 2008. Disponível em: <http://ifgu.auf.org/ media/document/40345193.pdf>. Acesso em: 02 out. 2018.

. Enseignement supérieur: internationalization et commerce. Paris: OCDE, 2004. Disponível em: <https://www.oecd-ilibrary.org/fr/education/ enseignement-superieur-internationalisation-et-commerce_9789264015074-fr >. Acesso em: 21 fev. 2017.

PARLAMENTO EUROPEU. Direction Générale des Polítiques Internes. L'internationalisation de l'enseignement supérieur. União Europeia: Étude, 2015. Disponível em: <http://www.europarl.europa.eu/RegData/etudes/ STUD/2015/540370/IPOL_STU(2015)540370_FR.pdf>. Acesso em: 08 fev. 2016.

ROSSI, W. Capitalismo e educação. $3^{\text {a }}$ ed. São Paulo: Moraes, 1980.

SCHULTZ, T. W. O valor econômico da educação. $2^{\mathrm{a}}$ ed. Rio de Janeiro: Zahar Editores, 1973. 
SHIROMA, E. et al. Decifrar textos para compreender a política: subsídios teórico-metodológicos para análise de documentos. Perspectiva, Florianópolis, v. 23, n. 02, p. 427-446, jul./dez. 2005.

OLGAÍSES CABRAL MAUÉS é Professora Titular da Universidade Federal do Pará. Licenciada em Pedagogia pela Universidade Federal do Pará, com mestrado em Educação pela Universidade de Brasília e doutorado em Sciences de L'éducation - Université des Sciences et Technologies de Lille III , Lille, França. Fez pósdoutorado na Université Laval, Quebec, Canada em 2002 e UFMG em 2011. Pesquisadora Produtividade do CNPq, Professora da graduação e do Programa de Pós-Graduação em Educação da UFPA. Ex Coordenadora do Programa de Pós-Graduação em Educação da UFPA. Ex Coordenadora do Fórum de Programas de Pós-Graduação do Norte, FORPRED Norte. Coordena Pesquisa, orienta em nível de graduação e pós-graduação. Coordena na UFPA o Grupo de Estudo e Pesquisa sobre Políticas Educacionais, Formação e Trabalho Docente. Coordenou o PPGED/UFPA de 2014 a 2015. É membro associado do Centre de Recherche Interuniversitaire sur la formation et la profession enseignante. (CRIFPE), pertencente à UNIVERSITÉ LAVAL- Quebec, Canadá. É associada à ANFOPE; ANPED; ANPAE. E-mail: olgaises@uol.com.br ORCID: https://orcid.org/0000-0002-6012-1432

ANDRÉ RODRIGUES GUIMARÃES é Doutor em Educação pela Universidade Federal do Pará (2014), Mestre em Desenvolvimento Regional pela Universidade Federal do Amapá (2008) e Licenciado em Pedagogia pela Universidade Federal do Pará (2003). Professor Adjunto III da Universidade Federal do Amapá. Atualmente é Coordenador do Programa de Pós-Graduação em Educação da Universidade Federal do Amapá (2018-2018), tendo exercido a função de vice-coordenador no mesmo Programa (2017-2018). Coordenador Estadual da ANPAE no Amapá. Tem experiência na área de Educação, com ênfase em Políticas Educacionais, atuando principalmente nos seguintes temas: expansão e financiamento da educação superior, trabalho docente, função social da escolarização, neoliberalismo e reformas educacionais. E-mail: andre_unifap@ yahoo.com.br

ORCID: https://orcid.org/0000-0003-1153-0771

Recebido em março de 2019

Aprovado em junbo de 2019 